\title{
THE EFFECT OF ANTIHISTAMINE SUBSTANCES AND OTHER DRUGS ON HISTAMINE BRONCHOCONSTRICTION IN ASTHMATIC SUBJECTS ${ }^{1}$
}

\author{
BY JOHN J. CURRY \\ (From the Evans Memorial and Massachusetts Memorial Hospitals, and the Department of \\ Medicine, Boston University School of Medicine)
}

(Received for publication April 16, 1946)

The ability of antihistamine substances, sympathomimetic amines and other drugs to counteract histamine bronchoconstriction in animals has received widespread attention ( 1 to 10 ). Such tests have not been applied to normal human subjects because of failure to demonstrate significant amounts of bronchoconstriction after doses of histamine that may be safely administered. However, the occurrence of bronchoconstriction in many asthmatic patients following the administration of histamine has been confirmed (11). It was also discovered that this sensitivity to histamine varied from person to person and in the same individual with the severity of the asthmatic symptoms. Moreover, during any one period of study, repeated intramuscular or intravenous injections of identical quantities of histamine produced similar amounts of bronchoconstriction. Thus, the tracheobronchial reaction to histamine in a sensitive subject provides a means of assaying the effectiveness of various antihistamine preparations, as well as of other drugs, in counteracting this type of bronchoconstriction.

\section{METHODS}

The methods used in this study were similar to those described in a previous "communication (11). Bronchoconstriction was demonstrated by a decrease in the vital capacity. The subjects were patients with mild continued asthma, all of whom had been studied previously and found to have sensitivity of the traoheobronchial tree to histamine. One patient, B. R., was again very cooperative, and we are grateful to her for the large number of studies made with her assistance. Control reactions to histamine were ascertained before any counteracting drug was administered, and in no instance was more than one such drug given during any period of study. All doses of histamine were injected intravenously, unless otherwise noted.

1 This work was supported in part by a grant from the Upjohn Company, Kalamazoo, Michigan.

\section{RESULTS}

Benadryl ${ }^{2}$ (B-dimethylaminoethyl benzhydryl ether hydrochloride) was synthesized by Rieveschl and Huber. Loew and his co-workers $(1,2)$ demonstrated that it has a potent antihistamine effect in animal experiments. Clinical reports (12) also indicate that it has been particularly effective against allergic symptoms thought to be histaminic in origin. In these reports, the adult dose of benadryl varies from 50 to $500 \mathrm{mgm}$. daily. In the present study, smaller amounts of the drug were used in order to determine the duration of its antihistamine effect on the respiratory tract against histamine bronchoconstriction.

In subject $B$. R., the vital capacity was reduced by a control injection of $0.02 \mathrm{mgm}$. of histamine from $3,020 \mathrm{ml}$. to $1,231 \mathrm{ml}$., a drop of $1,789 \mathrm{ml}$, and after the measurements had returned to the resting levels, a dose of $10 \mathrm{mgm}$. of benadryl in $16 \mathrm{ml}$. normal saline was injected intravenously during a period of $1 \frac{1}{2}$ minutes. No side effects from the injection were noted. Two and a-half minutes after the injection was completed, a second intravenous dose of $0.02 \mathrm{mgm}$. of histamine produced a drop in vital capacity of only $721 \mathrm{ml}$. With successive injections of $0.02 \mathrm{mgm}$. of histamine at half-hourly intervals, approximately the same amount of protection was afforded (Figure 1). The headache, flush and taste in the mouth, which previously occurred as side reactions after the injection of histamine, were also definitely diminished in intensity.

In another study on B. R. the control dose of $0.02 \mathrm{mgm}$. of histamine reduced the vital capacity from $2,999 \mathrm{ml}$. to $1,170 \mathrm{ml}$., a drop of $1,829 \mathrm{ml}$. When a dose of $30 \mathrm{mgm}$. of benadryl in $50 \mathrm{ml}$. of normal saline was injected intravenously during a period of 5 minutes, the patient noted a slight

2 Parke Davis and Company. 


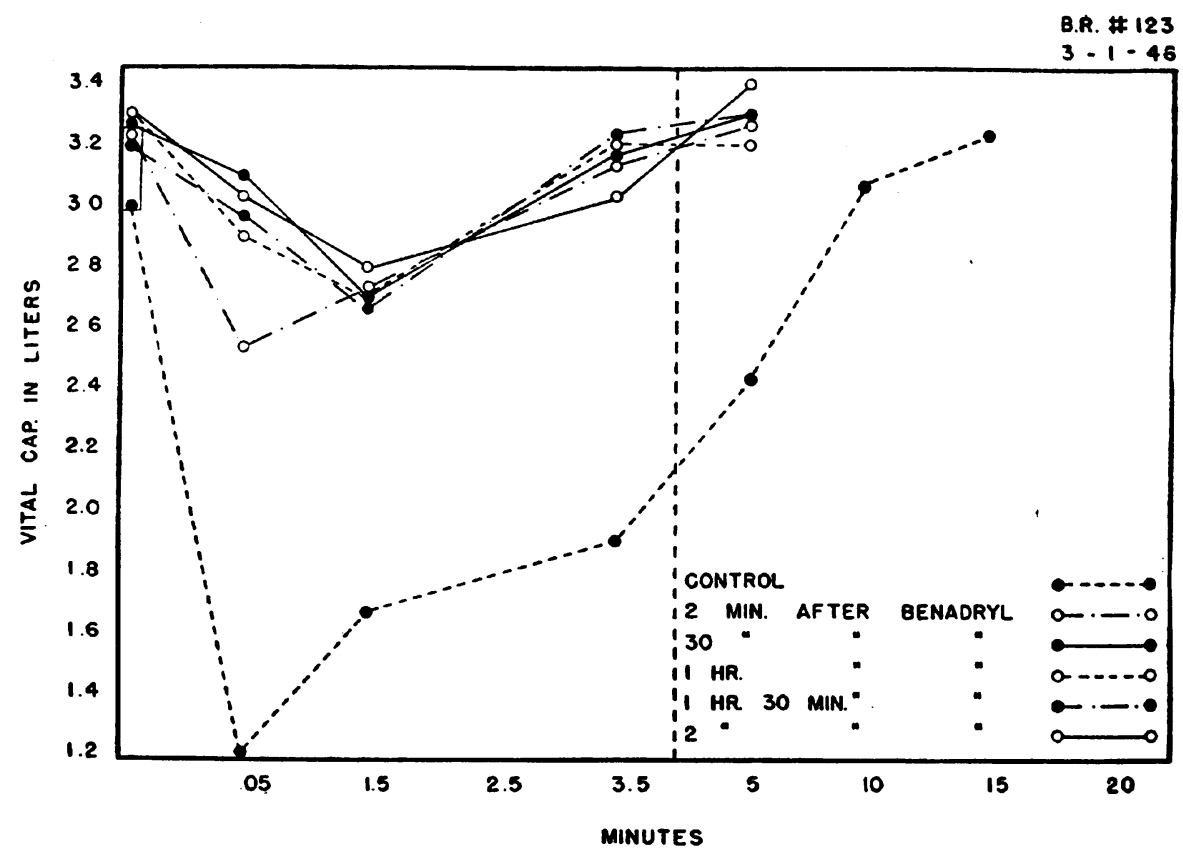

Fig. 1. Effect of 0.02 mgm. I.V. Histamine After 10 mgm. Benadryl I.V.

sensation of giddiness, and a mild pressor effect was found in the arterial pressure, especially in the diastolic level. Four minutes after the injection of benadryl was completed, the protection against the bronchoconstrictive and also the systemic effects of $0.02 \mathrm{mgm}$. of histamine was almost complete. Successive injections of $0.02 \mathrm{mgm}$. of histamine at half-hourly intervals over a period of $31 / 2$ hours showed a diminishing protection during the last 2 tests. Even then the drop in vital capacity at the $31 / 2$-hour test measured only $711 \mathrm{ml}$., compared to the control decrease of $1,829 \mathrm{ml}$. prior to the administration of benadryl (Figure 2).

In patient $\mathrm{V}$. B. a dose of $30 \mathrm{mgm}$. of benadryl in $50 \mathrm{ml}$. of normal saline, given intravenously, afforded complete protection against the bronchoconstrictive and systemic effects of $0.02 \mathrm{mgm}$. of histamine administered by vein, 3 minutes after the injection of benadryl was completed. In addition, the resting vital capacity was increased above previous control levels through the action of the benadryl. This same patient also obtained clinical relief from his asthmatic symptoms by 50 mgm. capsules of benadryl taken by mouth. This is of interest in view of the generally disappointing clinical results reported from treatment of asthma with benadryl (12). It is possible that the tracheo- bronchial reaction to histamine may provide a means of determining which patients will obtain relief clinically by the administration of benadryl. Further studies are in progress to establish whether there is a correlation between the effectiveness of benadryl in relieving the clinical symptoms of asthma and in counteracting histamine bronchoconstriction.

Pyribenzamine hydrochloride ${ }^{3}\left(\mathrm{~N}^{\prime}\right.$-pyridyl- $\mathrm{N}^{\prime}$ benzyl- $\mathrm{N}$ dimethyl ethylenediamine monohydrochloride) is another substance that has marked ability to counteract the pharmacological effects of histamine. Clinical studies have also shown it to be effective in relieving many allergic disturbances. Three of our asthmatic subjects were given $\mathbf{5 0}$ mgm. doses of pyribenzamine hydrochloride by mouth, and varying results were obtained. Subject V. B. showed almost complete protection against the systemic, as well as the bronchoconstrictive, effects of $0.02 \mathrm{mgm}$. of histamine $11 / 2$ hours after the oral administration of $50 \mathrm{mgm}$. of pyribenzamine hydrochloride. One-half hour after the drug was ingested, $0.02 \mathrm{mgm}$. of histamine produced a decrease of $3,189 \mathrm{ml}$. in the vital capacity, compared to the control decrease of $2,874 \mathrm{ml}$., but this decrease did not occur at the

\footnotetext{
${ }^{3}$ Ciba Pharmaceutical Products, Inc.
} 
30 -second test, and instead occurred at the $11 / 2^{-}$ minute test, indicating a delay in the onset of the bronchoconstriction. One hour after pyribenzamine was given, a repeat injection of $0.02 \mathrm{mgm}$. of histamine again failed to produce any decrease in vital capacity at the 30-second interval, while at the $1 \frac{1}{2}$-minute test there was a reduction. This time, however, the reduction measured only 899 $\mathrm{ml}$. A third injection of $0.02 \mathrm{mgm}$. of histamine $11 / 2$ hours after pyribenzamine hydrochloride failed to produce any significant reduction in the vital capacity (Figure 3). Thus, in this patient the drug apparently acted first to delay the onset of histamine bronchoconstriction, and finally to provide almost complete protection against both its bronchoconstrictive and systemic effects. $\mathrm{Pa}$ tient B. R., who had previously shown marked antihistamine protection from intravenous benadryl, failed to show any protection against the bronchoconstrictive or systemic effects of 0.01 mgm. of histamine given intravenously $1 / 2$ hour and 1 hour after the ingestion of $50 \mathrm{mgm}$. of pyribenzamine hydrochloride. Subject A. L., on the other hand, $1 \frac{1}{2}$ hours after the oral ingestion of $50 \mathrm{mgm}$. of pyribenzamine, exhibited both a slight amount of systemic protection from the effects of $0.02 \mathrm{mgm}$. of histamine, in that the flush, headache and taste in the mouth were less prominent, and a definite respiratory protection, in that histamine produced a drop of only $825 \mathrm{ml}$. in the vital capacity as compared with a decrease of $1,557 \mathrm{ml}$. in the control reaction to histamine prior to the administration of the pyribenzamine.

Atropine has been known to alter the gastric secretion evoked by histamine, and it was a matter of interest to determine what change it might produce in the reaction of the tracheobronchial tree to histamine in asthmatic individuals. In subject B. R., 4 inhalations from a nebulizer containing a $1: 1,000$ solution of histamine produced a decrease of $574 \mathrm{ml}$. in the vital capacity. Ten minutes following the intravenous administration of $1.2 \mathrm{mgm}$. of atropine sulfate, 4 inhalations were again taken, but failed to produce any bronchoconstriction. Twenty minutes after the atropine was given, $0.02 \mathrm{mgm}$. of histamine was injected intravenously. At the 30-second test the vital capacity had fallen $1,148 \mathrm{ml}$., but by 10 minutes had returned to the control range, a response less than might be expected from the amount of histamine injected (Figure 4). In this patient, therefore, atropine sulfate appeared to give some protection against the bronchoconstrictive effects of histamine.

Theophylline with ethylenediamine has been

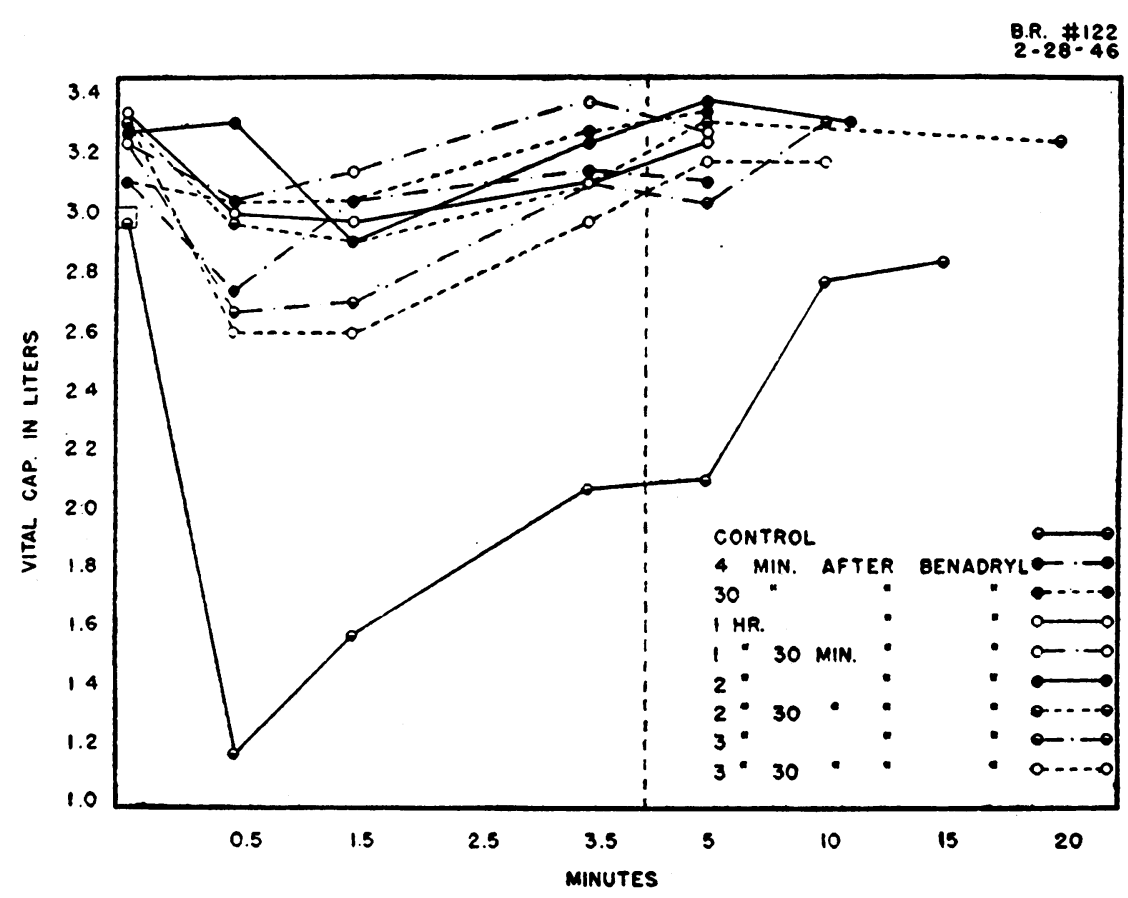

Fig. 2. Effect of 0.02 mgm. I.V. Histamine After 30 mgm. Benadryl I.V. 


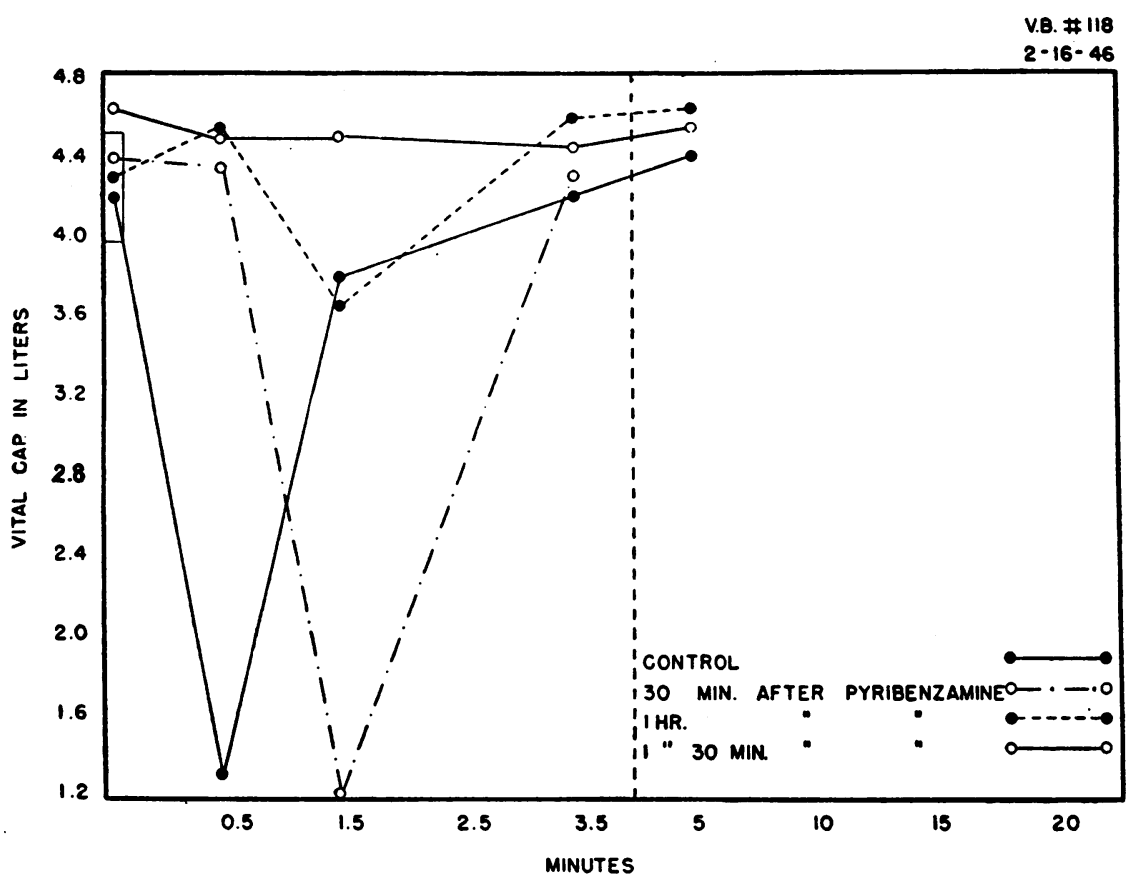

Fig. 3. Effect of 0.02 mgm. I.V. Histamine After 50 mgm. Pyribenzamine P.O.

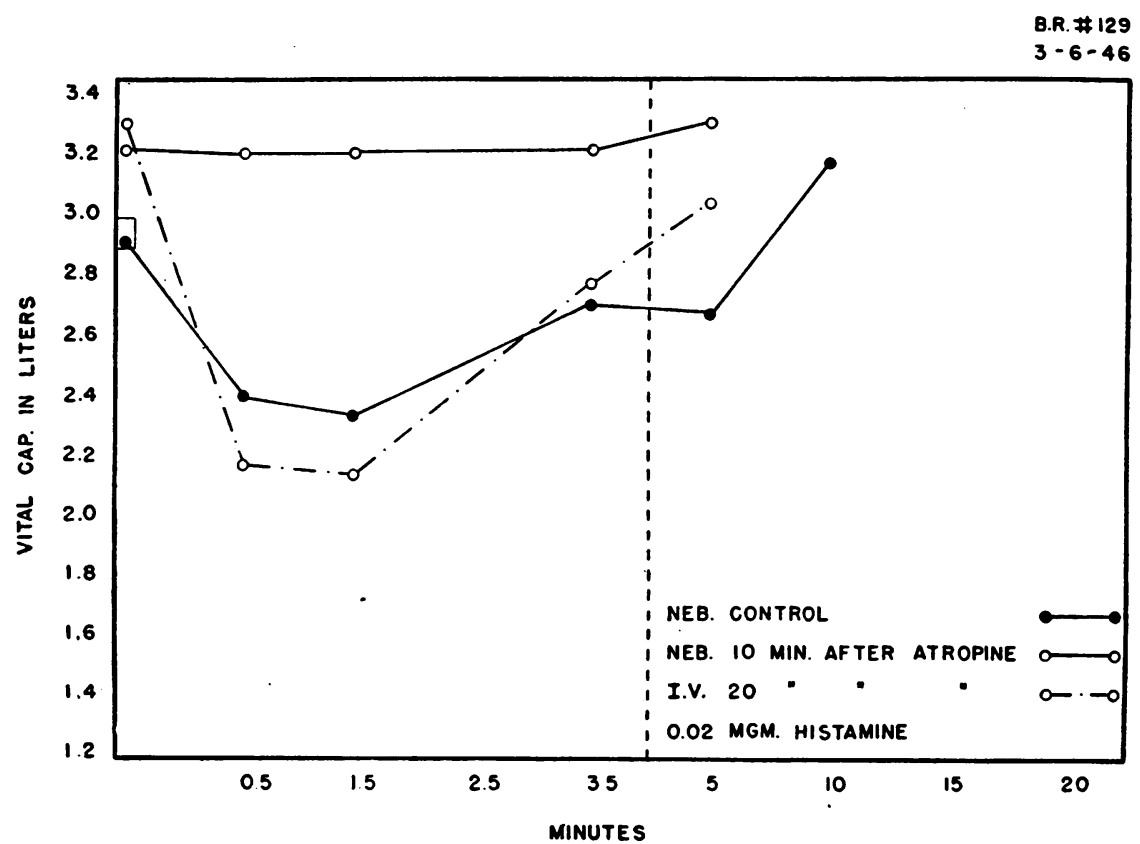

Fig. 4. Effect of Histamine After 1.2 mgm. Atropine Sulfate I.V.

generally considered a potent bronchodilating drug when administered intravenously. It has also been demonstrated to provide protection against the tracheobronchial activity of histamine in animals. In subject B. R., during a control period, the in- jection of $0.02 \mathrm{mgm}$. of histamine resulted in a decrease of $1,442 \mathrm{ml}$. in the vital capacity from an initial level of $2,926 \mathrm{ml}$. With a slow return over 30 minutes towards the previous levels of the vital capacities, this reaction indicated an increased sen- 
sitivity of the tracheobronchial tree to histamine at this time. A dose of $500 \mathrm{mgm}$. of theophylline with ethylenediamine diluted in $20 \mathrm{ml}$. of normal saline was then slowly given intravenously. As a result of the injection, the resting vital capacity was increased by $396 \mathrm{ml}$. over the previous control tests. Fifteen minutes after the injection of theophylline with ethylenediamine was completed, a dose of $0.02 \mathrm{mgm}$. of histamine was again administered, and a drop in vital capacity of only $156 \mathrm{ml}$. occurred. However, because of the increased resting vital capacity this drop did not bring the vital capacity measurements below those in the previous control series (Figure 5). This appears to confirm experimental work in animals showing a marked protection from theophylline ethylenediamine against histamine bronchospasm.

As expected, epinephrine gave rapid protection against histamine bronchoconstriction. Control injection of $0.04 \mathrm{mgm}$. of histamine intravenously produced a drop in vital capacity of $2,225 \mathrm{ml}$. When the vital capacity had returned to the resting range, a dose of $0.3 \mathrm{ml}$. of $1: 1,000$ epinephrine was injected into the deltoid. Ten minutes later $0.04 \mathrm{mgm}$. of histamine produced a decrease of only $205 \mathrm{ml}$. in the vital capacity. However, as a result of an increased resting vital capacity due to the epinephrine, the drop after the injection was well within the range of previous control vital capacities. This protection persisted for $1 \frac{1}{2}$ hours and then was lost, since at 2 hours and $2 \frac{1}{2}$ hours the same amount of histamine caused decreases in vital capacity only slightly less than those produced in the control state (Figure 6). In order to determine how small an amount of epinephrine might furnish protection in one subject, J. D., 0.1 ml. of 1:1,000 epinephrine was injected into the deltoid muscle. Ten minutes later, when a dose of $0.02 \mathrm{mgm}$. of histamine was injected, it produced a drop of only $485 \mathrm{ml}$. in the vital capacity as compared with the control drop of $1,935 \mathrm{ml}$. A half hour after the epinephrine was given, histamine produced a decrease of $815 \mathrm{ml}$. in the vital capacity, while at 1 hour it caused a decrease of $1,485 \mathrm{ml}$., indicating that the protective effect of the epinephrine was nearly dissipated. During a period when sensitivity to histamine was great in subject B. R., $0.4 \mathrm{ml}$. of 1:1,000 epinephrine gave less protection against histamine bronchoconstriction than it had on previous occasions, and the protection disappeared more rapidly (Figure 7). Epinephrine also protected to some extent against the flush after intravenous histamine, but did not affect the headache.

Ephedrine sulfate produced a marked protection against the tracheobronchial effect of histamine,

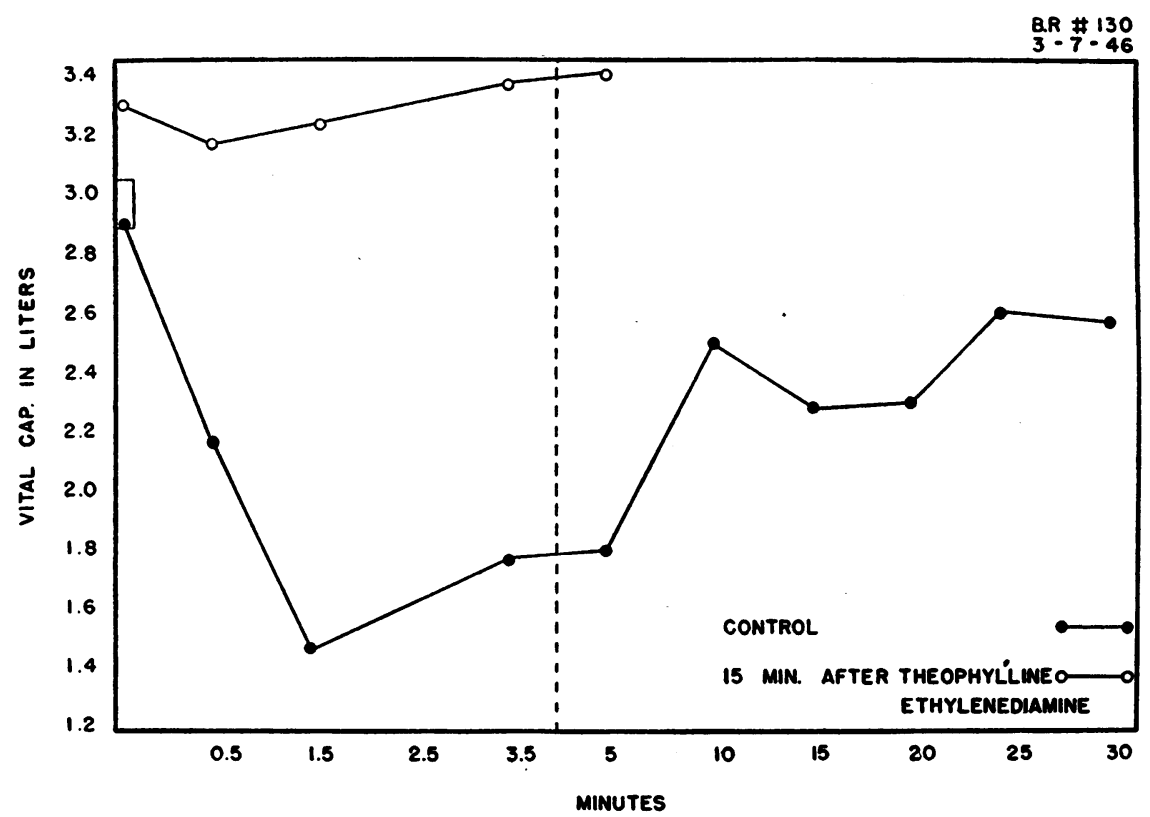

Fig. 5. Effect of 0.02 mgm. I.V. Histamine After 500 mgm. Theophylline Ethylenediamine I.V. 


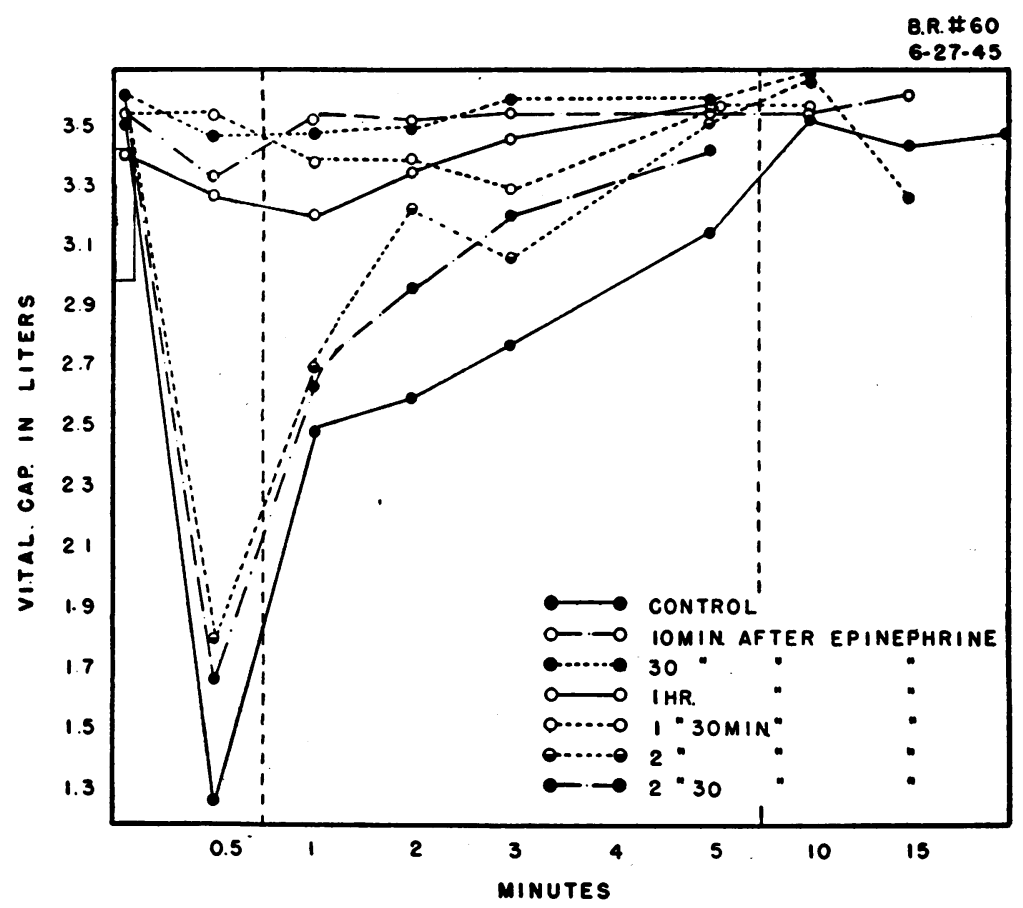

Fig. 6. Effect of 0.04 mgm. I.V. Histamine After 0.3 ml. $1: 1,000$ Epinephrine I.M.

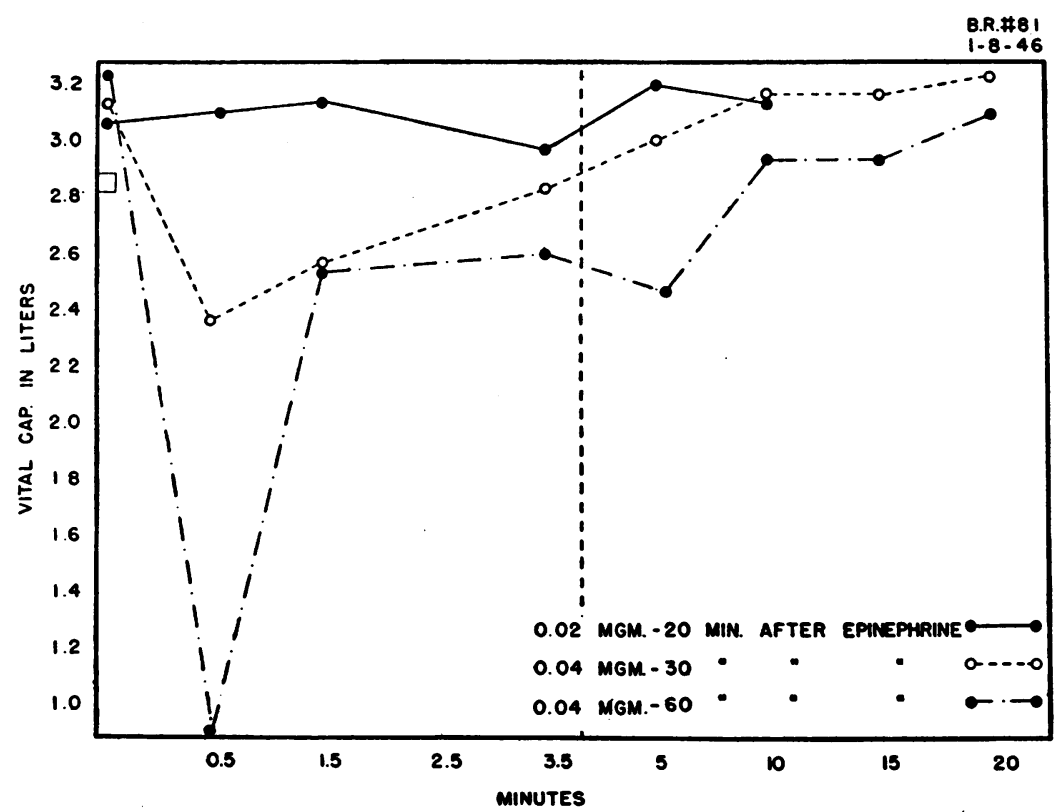

Fig. 7. Effect of I.V. Histamine After 0.4 mL. $1: 1,000$ Epinephrine I.M.

but the onset of protection was more gradual than that afforded by epinephrine. After $0.04 \mathrm{mgm}$. of histamine had been shown to produce a drop in the control vital capacity of $2,100 \mathrm{ml}$., a dose of $31 \mathrm{mgm}$. of ephedrine sulfate was given intra- muscularly in the deltoid. Ten minutes later 0.04 $\mathrm{mgm}$. of histamine caused a drop of $1,355 \mathrm{ml}$. in the vital capacity. One-half hour after ephedrine sulfate, $0.04 \mathrm{mgm}$. of histamine caused a decrease of only $440 \mathrm{ml}$., and in 1 hour, a decrease of 315 
$\mathrm{ml}$. in the vital capacity. Injections of histamine at 2 and 3 hours after the ephedrine sulfate had practically no effect on the vital capacity determinations (Figure 8). These results appeared to bear out what we know about the clinical effects of ephedrine sulfate by showing that there was a gradually increasing action over a period of an hour, and then a sustained effect. As yet, we have not determined how long the effect may persist.

\section{SUM MARY}

1. Previous studies have demonstrated that quantitative amounts of bronchoconstriction may be produced in certain asthmatic subjects by parenteral histamine. In the present communication, attention was given to the ability of certain antihistamine substances and other drugs to protect against this bronchoconstriction. The degree of bronchoconstriction after given doses of histamine was measured by recording the decrease in the vital capacity.

2. Benadryl administered intravenously produced a remarkable, rapid protection against both the systemic and bronchoconstrictive effects of parenteral histamine. Pyribenzamine hydrochloride given orally in $50 \mathrm{mgm}$. doses produced a slow and more irregular protection. No comparison of the 2 preparations could be made, since they were given by different routes, but it appears that with further study such a comparison can be made. In addition, further information should be obtained concerning the time of onset, extent and duration of effectiveness of the oral preparations.

3. Atropine sulfate furnished complete protection against the bronchoconstrictive effects of nebulized histamine in one instance, but only partial protection against intravenously administered histamine.

4. Theophylline with ethylenediamine given by the intravenous route afforded prompt and potent protection against the tracheobronchial effects of intravenous histamine.

5. Intramuscular epinephrine gave prompt and complete protection against the bronchoconstrictive effects of histamine, while intramuscular ephedrine sulfate also produced complete protection. With ephedrine, however, the protection was slow in onset, and only became complete 2 hours after the drug was administered. It appears that this method of study provides a means of measuring the bronchodilator activity of the various sympathomimetic amines.

\section{BIBLIOGRAPHY}

1. Loew, E. R., Kaiser, M. E., and Moore, V., Synthetic benzhydrylalkamine ethers effective in preventing fatal experimental asthma in guinea pigs exposed to atomized histamine. J. Pharmacol. and Exper. Therap., 1945, 83, 120.

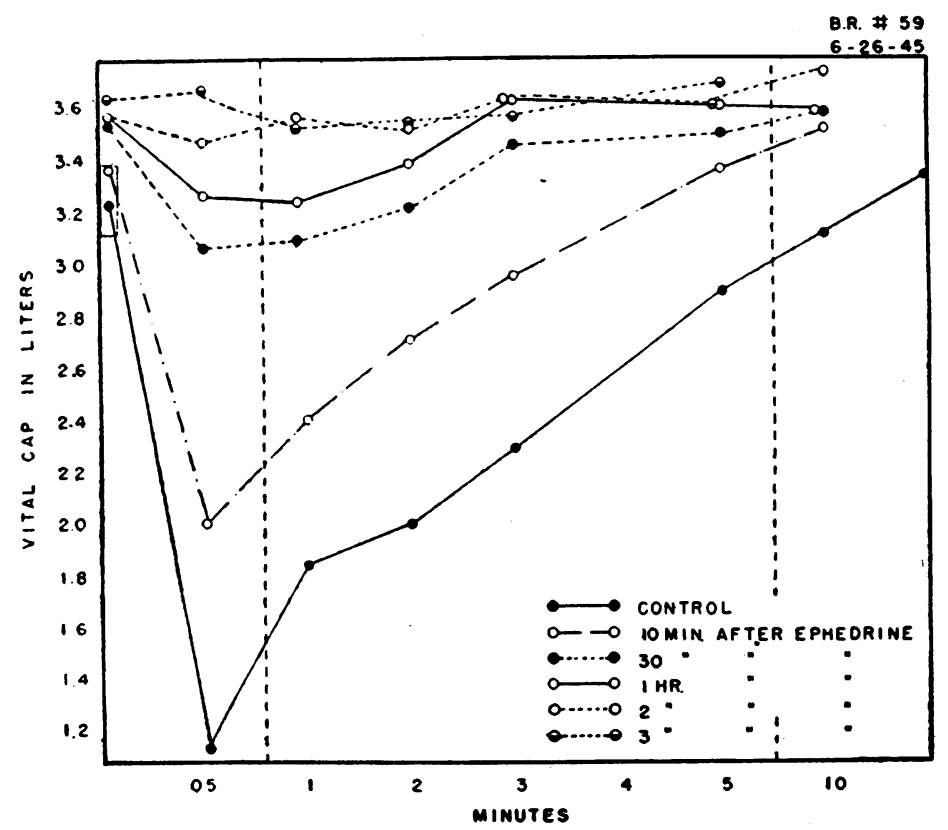

Fig. 8. Effect of 0.04 mgm. I.V. Histamine After 31 mgm. Ephedrine Sulfate I.M. 
2. Sherrod, T. R., Schloemer, H. F., and Loew, E. R., Pharmacologic studies of antihistamine compounds. Federation Proc., 1946, 5, 202.

3. Ellis, F. W., and Newsome, J. F., The effect of certain new antihistamine drugs on bronchial spasm. Federation Proc., 1946, 5, 176.

4. Selle, W. A., Benadryl as an antihistamine and antianaphylactic agent. Federation Proc., 1946, 5, 93.

5. Sollman, T., and Von Oettingen, W. F., Bronchial perfusion of isolated lung as a method of studying pharmacologic reactions of bronchiolar muscle. Proc. Soc. Exper. Biol. and Med., 1928, 25, 692.

6. Tainter, M. L., Pedden, J. R., and James, M., Comparative actions of sympathomimetic compounds, bronchodilator actions in perfused guinea pig lungs. J. Pharmacol. and Exper. Therap., 1934, 51, 371.

7. Swanson, E. E., Action of ephedrine, pseudoephedrine and epinephrine on the bronchioles. J. Pharmacol. and Exper. Therap., 1929, 36, 541.
8. Cameron, W. M., and Tainter, M. L., Comparative actions of sympathomimetic compounds: Bronchodilator actions in bronchial spasm induced by histamine. J. Pharmacol. and Exper. Therap., 1936, 57, 152.

9. Barlow, O. W., and Beams, A. J., A comparison of the bronchodilating action of several antiasthmatic agents after anaphylactic and histamine shock in the guinea pig. J. Pharmacol. and Exper. Therap., 1933, 47, 111.

10. Schaumann, O., Aspasan (ephedrine preparation) in therapy of histamine asthma. Experimental study. Munchen. med. Wchnschr., 1942, 89, 742.

11. Curry, J. J., The action of histamine on the respiratory tract in normal and asthmatic subjects. J. Clin. Invest., 1946, 25, 785.

12. Symposium on benadryl. Proc. Staff Meetings, Mayo Clinic, 1945, 20, 417. 